\title{
Assessment of Psycho - Social Services Intervention Programmes for Internally Displaced Persons in Maiduguri, Nigeria
}

Emenike J Umesi

Director, National Emergency Management Agency, Abuja, Nigeria and Visiting senior lecturer- Global Distance Learning Institute, Abuja. Nigeria Corresponding Author: Emenike J Umesi, Director, National Emergency Management Agency, Abuja, Nigeria and Visiting senior lecturerGlobal Distance Learning Institute, Abuja. Nigeria

Received date: January 16, 2021; Accepted date: February 15, 2021; Published date: February 23, 2020

Citation: Emenike J Umesi (2021) Assessment of Psycho - Social Services Intervention Programmes for Internally Displaced Persons in Maiduguri, Nigeria. J. Journal of Clinical Research and Reports, 7(1); DOI:10.31579/2690-1919/137

Copyright: (C) 2021 Emenike J Umesi, This is an open access article distributed under the Creative Commons Attribution License, which permits unrestricted use, distribution, and reproduction in any medium, provided the original work is properly cited.

\section{Abstract}

The study investigated the extent to which psychosocial services intervention programmes is being implemented for the internally displaced persons (IDPs) in the camps and to also find out how these programmes have been able to meet the needs of the affected persons. To achieve this objective, three research questions are generated. Subjects are 200 respondents that are selected from a target population of 1005 displaced persons in two (2) camps in Borno state, through simple random sampling. A questionnaire titled "Psychosocial Services Intervention Programmes Questionnaire" (PSSIPQ) was used for data collection while interview and focus group discussions were used for additional information gathering. The study concludes that psychological support services are available in the various camps but require deepening and some improvement.

Keywords: psychosocial; internally displaced persons; emergency management

\section{Introduction}

By January 2017, the total number of displaced persons in the world was about 40.3 million, and out of this figure, the newly displaced within their own countries by natural disasters, conflict or human rights violations at the end of December 2016, amounted to roughly 31.1 million. Sub Saharan Africa contributed $2.6 \mathrm{~m}$ of the $6.9 \mathrm{~m}$ figures for conflict-induced displacement. (IDMC, 2017)

Nigeria as at January 2018 had a total of 1,707,000 internally displaced persons out of the world's 40.0 million displaced persons. This displacement comes with a lot of incidents and experiences that leave the victims or affected persons traumatized. By the peculiar nature of these incidents, families have been separated, communities have been destroyed, and basic infrastructure damaged. The basic social and economic activities in the various communities have been disrupted making the need for humanitarian action inevitable. In the last few years, displacements have occurred in various parts of the country, coming along with its trademark of trauma and other social issues that also has a lot of impact on the mental health of the affected persons. Some of the states affected by displacement in the country include Adamawa, Borno, Yobe, Zamfara, Benue, Nassarawa, Cross River, Ebonyi, etc. The causes of these displacements range from human induced to natural disaster incidents. The resulting effects of these incidents go a long way to affect the displaced persons in the form of post disaster trauma. In cases of this nature, a consciously planned programme of psycho - social intervention is supposed to be in place and made available to all affected persons who require such mental health related services. It is based on the above, that this study is being carried out to assess the extent to which this sensitive aspect of social work intervention programmes is made available to the affected persons and whether it has helped to effectively mitigate the post disaster trauma challenges being faced by the internally displaced persons in the camps in Maiduguri.

\section{Psychosocial Services for Internally Displaced Persons}

In recent years, disasters have been on the increase and one of the fallouts of these incidents is the accompanying displacement of affected persons and the harassments and stress induced by the nature of the disaster incident. Most displaced persons from violence and conflict induced disasters suffer a lot of traumatic exposures that may require special interventions to resolve; these may result from loss of loved ones, sexual and gender-based violence, torture and near death and others, hence the importance of psychosocial support services.

According to IFRC (2017) psychological support is a critical part of emergency response which is geared towards ensuring that communities and individuals are able to heal the wounds inflicted on them by psychological incidents and assist them in rebuilding social structures after an emergency or disaster incident. It changes people from their passive victim status to active survivors. Psychosocial services entail an array of interaction-oriented post trauma rehabilitation services aimed at ensuring the physical, social, educational, health and especially mental wellbeing of an affected person, in this case a post disaster traumatized internally displaced person.

Psychosocial care involves a process through which an interested person shows care and concern towards an affected person and facilitates the person's transformation through self-knowledge. It is a relationship 
between an interested person and a person with a need. This relationship is usually a two-way personal relationship although sometimes it may involve more than two people. It is designed to help people to clarify and understand themselves and meaningfully interact with others with the aim of understanding their challenges and seek and a better approach to remedying them. Meaningful and well-informed choices, emotional and interpersonal problems are resolved through psychosocial support services. Psychosocial support services as defined means different things to different people and is provided in a variety of ways. For example, there are instances where counseling, play, exercises, puzzles etc. are given to resolve issues and create room for proper integration of an affected person. A teacher may be used by a student as a means to share all his worries, but, while doing that the teacher gives advice using counselling skills, but is he actually engaged in a counselling relationship? The teacher is not a counsellor but counsels as part of psychosocial support services.

Psychosocial support services according to UNHCR (2018) emphasizes the extension and mainstreaming of psychosocial support services into the following specialized areas of humanitarian intervention, namely

1. Community based protection programmes

2. Child protection programmes

3. Sex and Gender Based Violence (SGBV) prevention and response

4. Education programmes

5. Health programmes

6. Establish coordination mechanisms at country and local levels.

These specialized areas will require a lot of partnership and the involvement of specialists in the form of mental health professionals such as doctors, psychiatric nurses, clinical officers, psychiatrists, and these specialists will need to be available to support primary health care officials, social workers and community based specialists in ensuring the caregiving functions are effectively carried out. They will sometimes require some non-health workers to assist in carrying out these services when professional staff are not readily available.

Counselling is a critical aspect of psychological support as indicated by Ivey (2010) in her study on estate issues. Ivey looked at counselling in a secular context and described counselling as an activity concerned with helping people, manage their normal problems and opportunities and associates it with professional fields of human services such as psychology, guidance and social work, and to a limited extent psychiatry. Ivey suggest that other specialized areas which involve intense processes and difficulties in behavior such as psychotherapy is conducted by professionals. This area of psychosocial intervention is specialized in exploring, discovering and clarifying ways and manner of living more resourceful and satisfying life and the sole aim of counselling is to provide non-judgmental, safe and confidential environment for the adjustments to take place.

Counseling has existed in different forms with results varying in terms of outcomes over a long period of time. It has presently been given a pride of place in places like schools, churches and other institutions rendering psychosocial support to both the young and adults alike. The present-day differences and contradiction in the use and practice of counselling in the society has its history in the social and historical activities that has shaped and modelled modern day culture. The experience of various emotional and psychological events and development of other behavioral problem has guided the development of well-established ways of managing these challenges experienced by individuals.
Scivoletto and Morganti (2008) in their study has explained that the increase in the number and depth of socio-economic changes in the world has over the years led to a shift in the ways people manage their lives especially the IDPs, consequently, the remedies applied in the past cannot effectively handle all the challenges of the present, and this had made counseling an important intervention in the handling of Boys and girls, and young men and women in their relationship with their health, earning shells, knowledge, environment, and attitudes which will determine their progress or not in life.

Nielsen (2010) studied the role of psychosocial support in the rehabilitation of internally displaced persons in Lebanon. The study had a sample of 1000 internally displaced persons using a survey research design and population t-test to analyze the data obtained. The researcher in his findings explained that the rehabilitation counsellor wears many hats enabling him/her to function effectively in minimizing the functional limitation of an IDP and also for improving their opportunity for employment, coordination of physical, emotional, financial, social, medical, vocational and personal development services of the individual.

Choi (2011) noted that the complex and ever changing nature of the society's challenges and ever dynamic advances in science and technology has placed enormous duties on the education sector as its pivotal role of preparing citizens for faster and appropriate adaptation to changes is very paramount in surmounting challenges. Psychosocial support services, as an educational tool should assist displaced person especially the youths in overcoming their development challenges especially as it relates to social, moral, academic and intellectual capacities, and the disparities in education of the girl child in our society. These disparities can improve where counseling is made a priority in order to do away with these beliefs that have also permeated the camps and living modes of internally displaced persons and affected the selfimage of the girls and boys concerned.

Szymanski and Parker (2006) carried out a similar study on providing psychosocial services for internally displaced persons in Pakistan using 500 respondents and Chi-square statistical tool to analyze their responses. The result of the study showed that psychosocial support services significantly affect the rehabilitation of internally displaced persons in the study area. Additionally, the author explained that there is a need for the counsellor who doubles as a consultant to his clients to assist in accessing resources and gathering of data that will assist those persons to achieve their vocational targets. The counsellor would gather information about interests, aptitudes, and achievements of their targets in order to use this vocational evaluation to predict the future performances of the participants. But for post disaster trauma counseling (PDTC) the emphasis is on the individual's abilities as they are related to work and using them to make informed decisions on how to assist them adjust. It is therefore important for the participant to understand the important role assessment plays in the vocational counselling relationship.

The shift from lack of focus to client empowerment and informed choice as opined by Iyengar (2008) in his work is leading vocational evaluators and counsellors towards meeting the needs of their clients by adopting community-based assessment in ensuring that a proper career path is chosen. Despite this need, there has always been a resistance from the counsellors and evaluators to adopt this new strategy. In his opinion, the researcher believes that the rehabilitation process has as one of its important goals, the achievement of employment outcomes by their clients. This is consistent with their values especially with 1992 Reauthorisation and rehabilitation Act which ensures empowerment and informed choice of the affected population as outlined in the rehabilitation act of 1973 as amended which emphasizes competitive employment. These amendments reflect in the new direction of counsellors' approach to the rehabilitation of displaced persons. The psychosocial support officer's role plays an important part in ensuring that internally displaced 
persons adjust positively to enable them gain jobs that are in tandem with their skills, attitudes and training.

According to Rauch (2009), Post Disaster Trauma Counsellor's job which is a part of the psychosocial support team, involves social and personal counselling, should assist in directing students in the area of educational and vocational opportunities. This will correct the impression given of the African girl child who is portrayed as passive, submissive person and is seen but never heard and suffering of poor self-image and inferiority complex, is this perception enforced by the attitude of the society, teacher and parents. Personal counselling as encouraged will empower the girl child to develop positive attitude towards self and engender the need to acquire more knowledge and seek freedom. PDTC is important at this stage since it will enable the boys and girls to develop positive attitude towards each other and begin to contribute to the social wellbeing of their communities.

Mola (2013) asserted that post-disaster trauma counselling services to help internally displaced persons can take the form of psychosocial services which deals with difficulties with emotions and behaviour which arise out of experience encountered in the process of conflict. Any aspect of development after their encounter may result into an adjustment problem. It is imperative that care should be taken to address the issues. These issues which can be encountered by any one may include challenges such as Anxiety, challenges of career adjustment, anger over security and interpersonal conflicts, depriving feelings resulting from the events witnessed, guilt about a mistake resulting in great losses, grief over a loved one disillusionment, grief over parents disappearance, etc.

Similarly, Norris (2011) in his study on IDPs and post disaster trauma counselling for internally displaced people opined that vocational counseling is the most effective PDTC, he described it as contact at an individual level which leads to career advice and subsequent development.

Storbeck and Pittman (2008) enumerated the following as the goals and purposes of groups counseling for internally displaced people as a result of their study:

"To grow in self-acceptance and learn not to demand perfection, to learn how to trust oneself and others, to foster self-knowledge and the development of a unique self-identity, to lessen fears of intimacy, and learn to reach out to those one would like to be closer to, to move away from meeting other's expectations, and decide for oneself the standards by which to live. The goals also included, to increase self-awareness, and increase the possibilities for choosing and acting, to become aware of choices and to make choices wisely, to become more sensitive to the needs and feelings of others, to clarify values and decide whether, and how, to modify them, and, to find ways of understanding, and resolving, personal problems" (p.29).

The exposure to life threatening events, overwhelms infants and children and could lead to emotional distress and traumas. The manifestation of these traits could be in form of delays in development, changes in behaviour, and other severe health and psychological conditions. Stucki and Cieza (2014) explained that programming of psychosocial activities involve arranging modules which are aimed at managing the psychological and social advancement of people in order to enhance their resilience against factors that attack their behavioural wellbeing. To establish normal family life after a bloody conflict takes a lot of time and utilizes the return of family, normalcy and familiar routines that engage the mental abilities of family members to understanding that life is gradually normalizing.

The challenges from emergencies, which result in traumas, therefore, will require special attention to be managed. According to Riefels (2013) the extension of post trauma psychosocial services to the internally displaced persons has been recognized as an important step towards averting challenges of mental health towards victims of disasters. (North and Pfefferbaum, 2013; Norris, Friedman, Watson, 2002; Bonanno, Brewin, Kaniasty, \& LaGreca, 2010; Ritchie, Watson, \& Friedman, 2006). The Inter Agency Standing Committee guidelines for psychosocial disaster responses recommend a multilevel support strategy to be utilized depending on the situation of the internally displaced population (Inter-Agency Standing Committee, 2007). They can use community-based intervention, rendering of direct assistance, and support such as Psychological First Aid. They can also apply other mental health treatments such as eye movement desensitization and reprocessing therapy, or EMDR; or pharmacotherapy or trauma-focused cognitive behavioural therapy, or TF-CBT; to avoid the development of further complex mental health conditions.

The importance of this mental health service is very critical in disaster response, especially when it is a conflict driven emergency, where some of the affected persons witnessed the killing of their loved ones or the destruction of their properties or saw their loved ones defiled or themselves violated. This service acts as a catalyst for proper healing of the emotional and psychological wounds of the disaster. The use of this social therapy has been well researched in various regions of the world, but, direct studies have hardly been carried out in the West African region and has necessitated this study on its availability and adequacy in the present crisis rocking the area.

\section{Research Methodology}

The quantitative research design is used for this study. This design helped the researcher study use interviews, questionnaires and focus group discussion to ascertain the extent to which this service is being rendered to the affected persons. The population of the study consists of the 45,019 internally displaced persons located in eight (8) camps in Maiduguri according to the displacement matrix of the Internal Organisation for Migration (IOM) and the National Emergency Management Agency (NEMA). The sampling method was used to select 250 respondents, out of which 243 respondents finally participated. To carry out this study three research questions were used.

\begin{tabular}{|l|l|l|l|}
\hline & Camps & No. of families & No. of individuals \\
\hline 1. & Christian Association of Nigeria Centre & 932 & 7,897 \\
\hline 2. & Arabic Teachers College & 1,568 & 8,034 \\
\hline 3. & Teachers Village & 3,479 & 9,268 \\
\hline 4. & NYSC Camp & 1,100 & 4730 \\
\hline 5. & Mogolis Camp & 300 & 2,300 \\
\hline 6. & Bakasi Camp & 832 & 5,748 \\
\hline 7. & Shehu Sanda Kyarimi Camp & 568 & 2,028 \\
\hline 8. & Goni Kachallari Camp & 500 & 5014 \\
\hline
\end{tabular}

NEMA (2017)

Table 1: Selected Camps and Populations in Maiduguri, Borno State 


\section{Research Questions}

Research question 1: What types of psycho social services are being rendered in the internally displaced persons camp in Maiduguri?

Research question 2: Which organizations are rendering these services in the camps?

Research Question 3: To what extent has the post - disaster psycho social services

Been provided to the internally displaced persons?

\section{Findings and Discussion}

Research questions 1 and 2 were answered using interviews and discussions in the camps with the respondents, while the third research question was answered using the questionnaire. The focal group discussion was used to elicit responses and get reactions from those that are experiencing the traumas first hand.

The following services are present in the camps as enumerated by the respondents Community support services, specialized services for at risk groups such as widows, orphans, injured and handicapped persons etc. and direct support services for people with mental health issues. Majority of the people fall under the at risk groups while the mental health issues are handled at referral levels. The respondents listed the names of organisations involved in rendering these services to include International Office for Migration (IOM), Nigerian Red Cross, International Committee for Red Cross (ICRC), NEMA \& BOSEMA, UNICEF, UNHCR, FMWA and other NGOs in the camps. They explained that these organisations play the roles but some of them have improved tremendously in this area.

\begin{tabular}{|l|l|l|l|l|l|l|l|}
\hline S/N & Item Statement & Yes & Yes\% & No & No \% & No Response & No Response \% \\
\hline 1 & $\begin{array}{l}\text { Did you witness any traumatic event } \\
\text { during the conflict in your community? }\end{array}$ & 202 & 83 & 22 & 9.0 & 21 & 8.0 \\
\hline 2 & Did the events affect you? & 207 & 85 & 24 & 10.0 & 12 & 5.0 \\
\hline 3 & $\begin{array}{l}\text { Are you currently receiving any form of } \\
\text { counseling? }\end{array}$ & 114 & 47 & 92 & 38 & 37 & 15 \\
\hline 4 & Are the counseling sessions helpful? & 156 & 64 & 78 & 32 & 9 & 4.0 \\
\hline 5 & $\begin{array}{l}\text { In your opinion should the counseling } \\
\text { programme to be continued? }\end{array}$ & 214 & 88 & 17 & 7 & 12 & 5.0 \\
\hline
\end{tabular}

Table 2: Provision of Post disaster trauma counseling services

The third research question is analysed as follows with the aid of the tables below

The analysis presented on Table 2 showed that 202 respondents (83.\%), 22

$(9.0 \%)$ and $21(8.0 \%)$ said Yes, No and No response respectively on item 1; 207 (85\%); $24(10.0 \%)$ and $12(5.0 \%)$ said Yes, No and No response respectively on item $2 ; 114(47 \%) ; 92(38 \%)$ and $37(15 \%)$ said Yes, No and No response respectively on item 3; 156 (64\%), 78 (32\%) and 9 $(4.0 \%)$ said Yes, No and No response respectively on item 4 and 214 (88\%), $17(7 \%)$ and $12(5.0 \%)$ said Yes, No and No response respectively.

The focal group discussion revealed that the average time each of the respondents has stayed in a camp was 16 months with the least as 3 months. It also showed that more than $40 \%$ of the displaced persons have witnessed a death or torture of a close relative, except those who left early enough before the onset of the hostilities. Most of the IDPs still remember the ugly incidents and most of them agree that they have at one time or the other talked about the incident and about $60 \%$ of them agree that they have been treated for the trauma through counseling and are happy with the programme so far.

Many of the organisations in the camp have developed their own Mental Health and Psychosocial Support (MHPSS) activities, multidisciplinary psychosocial support mobile teams have been providing services to internally displaced persons (IDPs) and host community members, since 2014. According to IOM (2018) The teams composed of teachers, health care workers, counsellors and social workers offer a range of services including recreational activities for children and youth, informal education for adults, counselling and support groups. Through sensitization and focus group discussions, PSS teams are key in engaging with the local communities to identify and address cross cutting issues on
Sex/Gender based violence (SGBV), security, protection, and various life stressors in the conflict environment.

To strengthen the provision of MHPSS services, the organisations both local and international additionally support existing specialized mental health service facilities through the establishment of referral mechanisms, the rehabilitation of psychiatric wards, the training of mental health care workers and the deployment of psychiatric nurses into hard-to-reach areas.

The project also offers integrated livelihood opportunities, as well as trainings on MHPSS interventions and MHPSS mainstreaming into the humanitarian response sectors and partners - including government, nongovernmental actors, community leaders, United Nations agencies and civil society organizations.

Additionally, given the large scale protection concerns in the north east, they are ensuring protection mainstreaming throughout their emergency response and have rolled out GBV trainings for various sectors, conducting safety assessments, and working with partners to ensure GBV mainstreaming throughout the humanitarian response.

\section{Conclusion}

Psycho social service is a prominent part of the maintenance and care segment of the response phase of the disaster management cycle. It plays an important role especially in crisis driven disasters such as wars and insurgency. The post disaster traumas experienced by affected persons are the effects of punishment suffered by the individuals or their close relatives. It could also be as a result of experiences of other affected persons as observed by the individuals. It is therefore very important that these services be effectively rendered with the intention of promoting sense of safety and security, establishment of trust, strengthening of relationships, enhancing resilience and ensuring sustainability. 


\section{Implications for World Humanitarian Leadership}

Post disaster trauma is basically one of the most devastating effects of disaster incidents and it's especially delicate for the affected persons and could result to Post Traumatic Stress Disorder (PTSD) and would require a lot of attention for its management to be effective. One of the best known ways of managing this scourge is the application of psycho social services. It's been known to be very effective for persons affected by crisis driven events or incidents. This study therefore reviewed the application of this tool in the various camps in the north east using the two camps in Maiduguri as case studies. The results of this study will go along way to assist leaders in the humanitarian sector in the approaches to managing affected persons in various camps all over the globe in determining the type of officers required in the camps and the various strategies to be adopted in case psycho social services may be applied as a solution.

\section{References:}

1. Bonanno G. A, Brewin C. R, Kaniasty K, LaGreca A. M. (2010). Weighing the costs of disaster: Consequences, risks, and resilience in individuals, families, and communities. Psychological Science in the Public Interest. 11(1): 1- 49.

2. Choi, J. H. (2008). Multimodal early rehabilitation and predictors of outcome in survivors of severe traumatic brain injury. The Journal of Trauma, 65, 1028-1035.

3. Inter-Agency Standing Committee (2007). IASC guidelines on mental health and psychosocial support in emergency settings. Geneva: IASC.

4. International Displacement Monitoring Center (2014). Internal displacement:Global overview of trends and developments in 2013. Geneva, IDMC.

5. International Federation for Social Work (1996). Policy statement on human rights. IFSC Berne, Switzerland.

6. International Organisation for Migration/ National Emergency Management Agency (2015). Displacement tracking matrix for North East, Nigeria, October - December 2014. Abuja, Nigeria. IOM Press.

7. Ivey, E. B. (2010). How investor behavioral factors influence real estate investment satisfaction and reinvestment intention in Penang. Malaysia.

8. Iyengar, K. P. (2008). Targeted early rehabilitation at home after total hip and knee joint replacement: Does it work? Disability and Rehabilitation, 29, 495-502.

9. Jenkins, T. B. (2008). Global refugee trends, statistical overview of populations of refugees, asylum-seekers, internally displaced persons, stateless persons, and other persons of concern. UNHCR. Geneva, Switzerland. UNHCR.

10. Mola, E. (2013). Integrating internally displaced persons empowerment as an essential characteristic of the discipline of general practice/family medicine. The European Journal of General Practice, 14, 89-94.

11. National Emergency Management Agency, (NEMA, 2014). National emergency profile. Nigeria. NEMA. Abuja.

12. NEMA/IOM (2015). Displacement tracking matrix: Round 10. IOM Abuja

13. Nicolai, S. (2013). Education for emergency: A tool kit for starting and managing education in emergencies. London: Save the Children.

14. Nielsen, O. P. (2010). The role of counselors in rehabilitation of internally displaced persons in Lebanon. India. Social Science and Medicine, 61(10), 2212-2220.
15. Norris, F. H., Friedman, M. J., \& Watson P. J. (2002). 60,000 disaster victims speak: Part II. Summary and implications of the disaster mental health research. Psychiatry. 65 (3),240-260.

16. North, C. S, \& Pfefferbaum, B. (2013). Mental health response to community disasters: A systematic review. Journal of the American Medical Association. 310 (5), 507-518.

17. Onyencho,V.C, Kwajaffa,P.S., Abdu,W.I., Ali M.A., Placidus, O, Mohammed, J.S., \&Wakil Musa Abba,W.M. (2017) Assessment of Psychosocial Needs among Internally Displaced Persons

18. (IDPS) In Maiduguri Based On the Humanitarian Emergency Settings Perceived Needs Scale (HESPER) IOSR Journal Of Humanities And Social Science (IOSR-JHSS) 22, (7), Ver. 2 (July. 2017) 17-22

19. Rauch, C. (2009). Impact of inadequate safe water resources on the Acholi-Pii caseload refugees in Kyangwali refugee settlement, Hoima District, Uganda, AktionAfrikaHilfe, Uganda.

20. Reifels, L. (2013). Lessons learnt about psychosocial responses to disaster and mass trauma: An international perspective. European Journal of Psycho-Traumatology.

21. Ritchie, E. C., Watson, P. J., \& Friedman, M. J., (2006, eds.). Interventions following mass violence and disasters: Strategies for mental health practice. New York: Guilford Press.

22. Robert, K. \& Breiseth, L. (2008). How to support refugee students in the classroom. Pearson. London.

23. Schultz, B. A. (2013). Basic needs of internally displaced in Somalia. Trans Royal Society Tropical. Medicine Hygiene, 76 (4), 373-377.

24. Scivoletto, T. \& Morganti, B. (2008). Keeping clean water clean in a Malawi refugee camp:A randomized intervention trial. Bull. World Health Organization. 79, 280-287.

25. Sifnoes, P. E. (1972) A concept of emotional crisis. Mental Hygiene. 44 (2) 169-179.

26. Storbeck, C. \& Pittman, P. (2008). Early intervention in South Africa: Moving beyond hearing screening. International Journal of Audiology, 47, 36-43.

27. Stucki G, \& Cieza A. The international classification of functioning, disability and health (icf) core sets for rheumatoid arthritis: A way to specify functioning. Ann Rheum Dis. 2004;63 Suppl 2: ii40-ii45.

28. Sulaimon-Hill C. \& Thompson, S. C. (2011). Sampling challenges in a study examining refugee resettlement. $B M C$ International Health and Human Rights, 11, $24-30$.

29. Szymanski, F. \& Parker, T. (2006). The need for counseling services among internally

displaced persons in Pakistan. World Health Organ. 79, 280-287.

30. Telford, J., Cosgrave, J., \& Houghton, R. (2014). Joint evaluation of the international

response to the Indian ocean. European Board of Physical and Rehabilitation Medicine, 39: 279-285.

31. Telford, J., Cosgrave, J., \& Houghton, R. (2006) Joint Evaluation of the InternationalResponse to the Indian Ocean Tsunami: Synthesis Report. Tsunami Evaluation Coalition, London, UK.

32. Uddin Khan, M., \& Shahidullah, M. (2002). Role of water and sanitation in the incidence of cholera in refugee camps. Trans Royal Society Tropical. Medicine Hygiene, 76(3), 373-377.

33. Wietse, A.L., Corrado, B., Ananda, G., Derrick, S., Betancourt, T., Souza, R., Golaz, A., \& Omeren, M.V. (2010). Mental health and psychosocial support in humanitarian setting: Linking practice and research. British Journal of Psychiatry, 196, 69 -74. 